NEWS

\title{
China drought highlights future climate threats
}

\section{Yunnan's worst drought for many years has been exacerbated by destruction of forest cover and a history of poor water management.}

\section{BEIJING}

Born into a farming family in south Yunnan province, China, Zhu Youyong's life has always been tied to the soil. At the age of 54, however, Zhu - now president of Yunnan Agricultural University in Kunming - says he "has never seen such severe drought in Yunnan".

Since last September, the province has had $60 \%$ less rainfall than normal. According to the Ministry of Civil Affairs, 8.1 million people $-18 \%$ of Yunnan's population - are short of drinking water, and US\$2.5-billion worth of crops are expected to fail.

Scientists in China say that the crisis marks one of the strongest case studies so far of how climate change and poor environmental practice can combine to create a disaster. They are now scrambling to pin down exactly what caused the drought, and whether similar events are likely to hit the region more often in the future.

Meanwhile, with most of the province's winter crops ruined, local farmers need immediate help. Zhu has been going from
"If it still doesn't rain in late May, the consequences will be unthinkable."
Some say it is the worst in over a century. Xu is a contributor to a report on climate change in Yunnan and its myriad impacts ${ }^{2}$. Sponsored by CAS and the China Meteorological Administration, the report shows that Yunnan has got warmer and drier in the past half-century. Since 1960 , the number of rainy days has decreased, whereas the number of extreme events, such as torrential rains and droughts, has increased.

Some suggest that this year's drought in Yunnan might be caused by the El Niño/Southern Oscillation (ENSO), an atmospheric circulation system that originates in the western Pacific Ocean and brings rainfall to Southeast Asia. During El Niño years the wind from the Pacific weakens, leading to droughts in the region.

"We've had a moderately strong El Niño event since October," says Dan Bebber, a climate researcher at the Earthwatch Institute in Oxford, UK, a non-profit environmental group. Although Yunnan is not directly under the influence of ENSO, "there is a statistical relationship between El Niño and the monsoon system in southwestern China through farmers to grow different crops together in the same field, rather than as a monoculture. Intercropping can boost yields by up to $30 \%$, and could help to avoid food shortages in the region later this year ${ }^{1}$. This summer, $80 \%$ of the farmland in Yunnan - a staggering 2.9 million hectares - will use the technique. But success will depend on a break in the weather. "If it still doesn't rain in late May, the consequences will be unthinkable," says Zhu.

\section{Dry spell}

It is not news that China is seriously short of water, but its southwestern region - including the Yunnan, Guizhou, Guangxi and Sichuan provinces and Chongqing municipality usually sees ample precipitation. This year, however, the rains did not come, and people there want to know why.

"Yunnan does experience droughts every few decades," says Xu Jianchu, an ecologist at the Kunming Institute of Botany, an institute of the Chinese Academy of Sciences (CAS). But the severity of this year's drought is unusual. mechanisms that are unclear", he says.

Indeed, the CAS report suggests that in previous strong El Niño years, the rainy season in Yunnan, which spans May to October, was delayed, with less rain in the summer and more rain in the autumn. But climate models are divided on how climate change will affect ENSO, with some showing increasing intensity and others decreasing intensity, says Bebber.

Climate change is not the only factor affecting the drought. Deforestation in mountainous Yunnan is also being blamed. "Natural forests are a key regulator of climate and hydrological processes," says $\mathrm{Xu}$, who is also China's representative at the World Agroforestry Centre, an international think tank headquartered in Nairobi, Kenya.

The forest's thick litter layer of organic materials can absorb up to seven times its own weight in water, says Liu Wenyao, an ecologist at the Xishuangbanna Tropical Botanical Garden (XTBG), a research institute of CAS in Menglun in southwestern Yunnan. Natural forests also have an extensive network of roots that

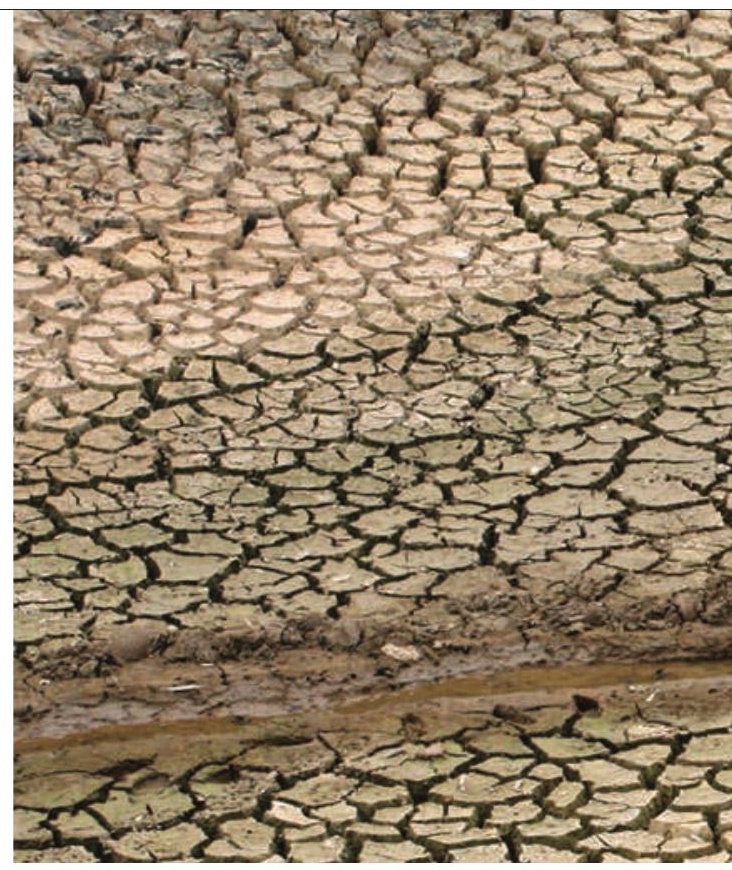

keep the ground moist, and the canopy can trap water vapour, creating a dense fog that keeps the myriad plant species alive during dry seasons.

But in Xishuangbanna prefecture, renowned for the natural splendour of its tropical rainforests, forest clearance between 1976 and 2003 shrank the primary-forest cover to $3.6 \%$ of its 1976 value $^{3}$. The rainforest has been replaced by rubber trees - known as 'water pumps' by locals because of their insatiable thirst - which now cover $20 \%$ of the prefecture's land.

In the Ailao mountains north of Xishuangbanna, where it is too cold to grow rubber trees, plantations of fast-growing but thirsty eucalyptus are replacing primary forest to feed the paper industry. In other parts of Yunnan, logging, mining, quarrying and increasing human settlement have cleared huge areas of forest. The results are an increase in soil erosion, landslides and flash floods.

"Such large-scale deforestation removes the valuable ecological services natural forests provide," says Liu. "The impact of deforestation on hydrological processes becomes particularly acute during prolonged droughts." The region could also be plagued by other natural hazards: with drought the risk of forest fire increases, whereas wetter monsoon seasons could see more floods wreaking havoc.

Many scientists are now worried that severe droughts, such as Yunnan's, will become more common across southeast Asia. In addition to the effect on humans, "the impact on biodiversity could be huge," says Jennifer Baltzer, an ecologist at Mount Allison University in Sackville, New Brunswick, Canada.

As existing plant species struggle to cope with the drought and die, they are replaced by hardier 


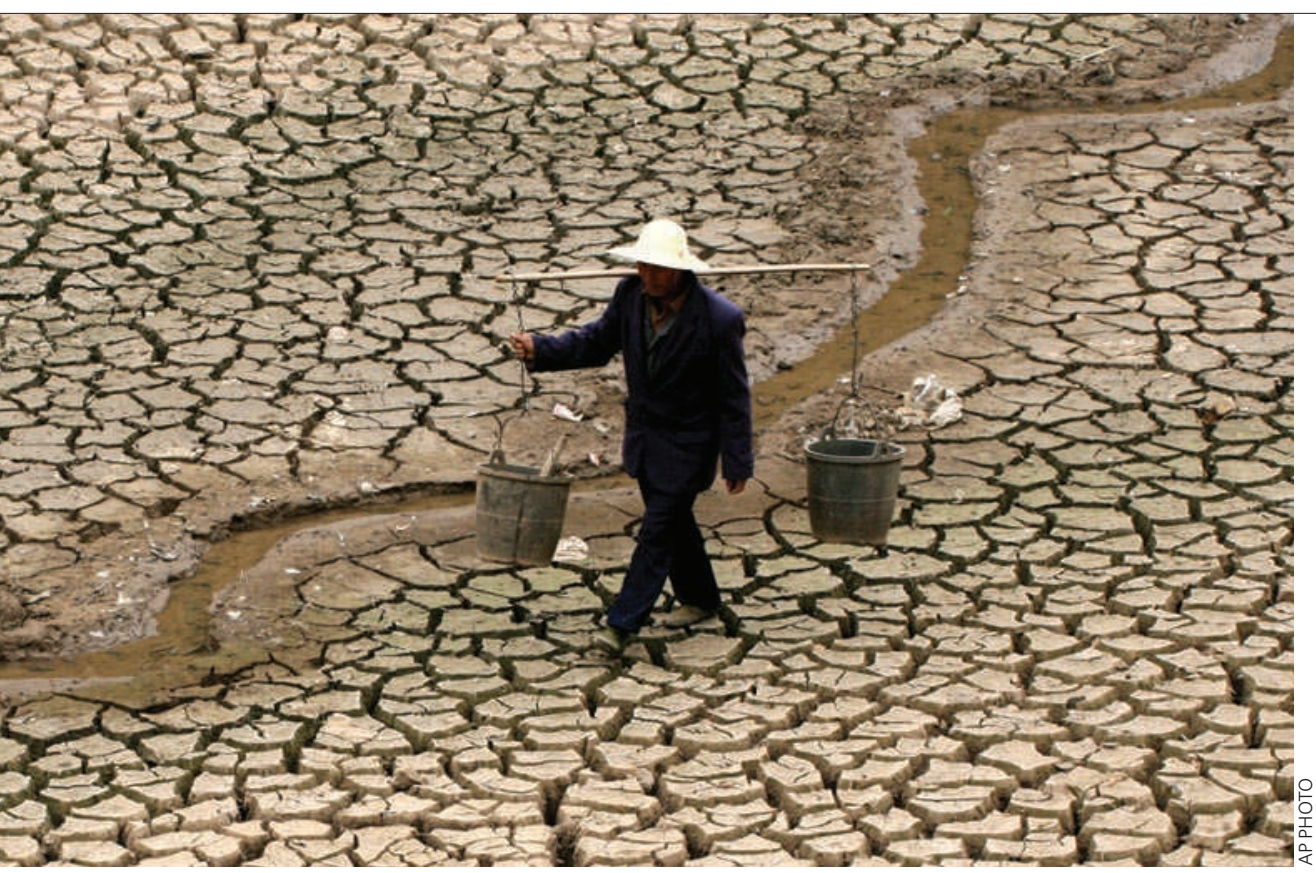

The drought in Yunnan province has left millions without water.

plants. Zhu Hua, an ecologist at XTBG, and his colleagues have already noted a $10 \%$ increase in the abundance of liana species over the past few decades in southwestern Yunnan's tropical forests ${ }^{4}$. Cao Kunfang, also an XTBG ecologist, says that lianas have a deep root system that allows them to absorb water deep in the soil ${ }^{5}$. They can also minimize evaporation by closing the minute stomatal pores in their leaves. But without a large trunk, lianas are poor at absorbing carbon dioxide - and even worse once their stomata close. "Having more lianas in tropical forests could compromise their function as a carbon sink," says Cao.

\section{Last-minute scramble}

As government officials scramble to deal with the emergency in Yunnan, the province's water management is being scrutinized. Most of its reservoirs were built more than 50 years ago, and half are either disused or do not function properly. Many of Yunnan's natural lakes are severely polluted and unusable, says Ma Jun, director of the Institute of Public and Environmental Affairs, a non-governmental organization in Beijing. Xu says that the region has not enough small-scale infrastructure - ponds, small reservoirs and canals - to distribute clean water to the hardest-hit areas. "There is an urgent need to develop an effective hydrological network in the province," he says.

In recent years the region has instead focused on building huge reservoirs and hydropower stations, Xu says, because of the economic and political capital that such projects offer. Overall, the central government has been reactive, tackling droughts when they come rather than preparing for the worst, adds Yu Chaoqing, a hydrologist at the Beijingbased China Institute of Water Resources and Hydropower Research, part of the government's Ministry of Water Resources.

Throughout southwestern China, where 2,000 drought-relief workers are drilling wells around the clock, the location of groundwater remains elusive because few geological surveys have been done. "It's a last-minute scramble because only $10 \%$ of the drought-ridden region has been surveyed," says Hao Aibing, a geologist at the China Geological Survey in Beijing, who is helping to locate groundwater in Yunnan, Guizhou and Guangxi provinces. "Even if we get live water wells, the water quality remains an issue," he says. "We just know so little about the groundwater in the region."

Researchers are adamant that lessons must be learned from this year's drought in Yunnan. "Extreme weather events are likely to happen more frequently in the future," says Xu, referring to the findings of the CAS report. "I hope we will be better prepared when the next natural disaster strikes."

Jane Qiu

\footnotetext{
1 Li, C. et al. PLoS ONE 4, e8049 (2009).

2. Zhou, Y., Lu, X.-X., Xu, J.-C., Zhang, H. \& Jiang, T. (eds) Systematic Assessment of Climate Change Impact in Yunnan Province (China Meteorological Press, in the press).

3. Li, H., Ma, Y., Aide, T. M. \& Liu, W. Forest Ecol. Manag. 255, 16-24 (2008).

4. Zhu, H., Xu, Z.-F., Wang, H. \& Li, B.-G. Biodivers. Conserv. 13, 1355-1372 (2004).
}

5. Zhu, S.-D. \& Cao, K.-F. Plant Ecol. 204, 295-304 (2009).

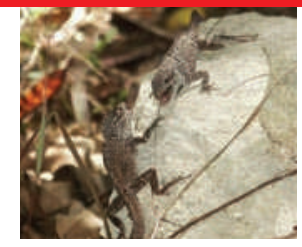

WHIPPING UP A LITTLE NATURAL SELECTION Manipulated islands reveal secrets of lizard adaptation. go.nature.com/MVTNxc

\section{Shake-up for fusion team}

The international fusion experiment ITER may get a new director-general after suffering delays and cost overruns. Osamu Motojima, a distinguished Japanese physicist, is being floated as the project's new chief, Nature has learned. The appointment, if made, may trigger further changes for the project. "I wouldn't be surprised if there's a huge shakeup in ITER management under him," said one fusion scientist familiar with the project.

Motojima would replace Kaname Ikeda, who has led the programme since its inception in 2007. Ikeda was originally appointed for a five-year term, and his departure would be the second high-level management change in recent months. In February, Europe's project head, Didier Gambier, was replaced by British physicist Frank Briscoe (see Nature 463, 721; 2010).

ITER spokesman Neil Calder said that the organization would consider management changes at the next council meeting in June. However, he would not confirm whether Motojima is a candidate for the directorship.

Researchers hope that ITER, based in the south of France, will prove the viability of nuclear fusion as a power source. The doughnut-shaped reactor will heat and squeeze hydrogen isotopes until they fuse together, forming helium. The process is expected to release ten times the power it consumes. ITER's seven members - Europe, Japan, the United States, South Korea, China, Russia and India - hoped to build the project by 2016 at a cost of $€ 5$ billion (US\$6.3 billion). But that cost is expected to double, and first experiments are now set for late 2019. On 5 May, the European Commission announced that it faces $\mathrm{a} € 1$.4-billion funding gap for construction between 2012 and 2013.

Motojima has a long career in fusion research. From 1999 to 2002, he oversaw construction of a fusion machine called the Large Helical Device (LHD) at the National Institute for Fusion Science in Toki City, Japan. The LHD uses a twisted loop of magnets to wrangle hot gas, a more complex set-up than the doughnut-shaped ITER device. Despite this, Motojima saw the LHD completed on schedule, says Hutch Nielson of Princeton Plasma Physics Laboratory in New Jersey. "I think Motojima's record there was a complete success," he says. Geoff Brumfiel 